\title{
Editorial: Fouling in Membrane Filtration Systems
}

\author{
Luca Fortunato $^{1 *}$, Frank Lipnizki ${ }^{2}$ and Ludovic F. Dumée ${ }^{3}$ \\ ${ }^{1}$ Division of Biological and Environmental Science and Engineering (BESE), Water Desalination and Reuse Center (WDRC), King \\ Abdullah University of Science and Technology (KAUST), Thuwal, Saudi Arabia, ${ }^{2}$ Department of Chemical Engineering, Lund \\ University, Lund, Sweden, ${ }^{3}$ Department of Chemical Engineering, Khalifa University, Abu Dhabi, United Arab Emirates
}

Keywords: fouling, cleaning, membrane processes, desalination, wastewater treatment

\section{Editorial on the Research Topic}

\author{
Fouling in Membrane Filtration Systems
}

Membrane processes are the fastest-growing separation technologies for a broad range of applications, including seawater desalination, wastewater treatment, industrial applications, biorefineries, biotech, and food processes (Charcosset, 2006; Takht Ravanchi et al., 2009; Mohammad et al., 2012; Favre). Fouling is caused by the accumulation of rejected material/ particles on the membrane surface or in the membrane pores during filtration. To this extent, membrane fouling is acknowledged as the main operational challenge in separation and purification processes, providing additional resistance to the filtration and increasing the energy demand of the whole process, reducing the membrane lifetime (She et al., 2016). Despite recent progress in the field, fouling is still considered a major challenge encountered in membrane processes (Ang et al., 2017). Major challenges and opportunities in the area include the development of new materials, as well as better and less chemically and energy intensive chemical and physical treatments (Fortunato et al., 2019; Scarascia et al., 2021). Better module

\section{OPEN ACCESS}

Edited and reviewed by: Eric Favre,

Université de Lorraine, France

${ }^{*}$ Correspondence: Luca Fortunato luca.fortunato@kaust.edu.sa

Specialty section: This article was submitted to Separation Processes, a section of the journal Frontiers in Chemical Engineering

Received: 10 November 2021 Accepted: 15 November 2021 Published: 16 December 2021

Citation: Fortunato L, Lipnizki F and Dumée LF (2021) Editorial: Fouling in Membrane Filtration Systems.

Front. Chem. Eng. 3:812625. doi: $10.3389 /$ fceng.2021.812625 design and implementation of continuous remediation strategies also represent key strategies to reduce the impact of fouling onto the processes and their performance (Jiang et al., 2017). As fouling is inherent to any concentration process, it will always occur, and routes to reduce its impact must be further developed to tackle operational challenges through synergistic approaches. In addition, the presence, within the foulant layer, of sometimes valuable resources also represents an opportunity from a resource recovery perspective, and recent fouling mitigation approaches encompass resource extraction strategies to create an integrated Circular Economy (Zhang et al., 2010; Vu et al., 2021).

This Research Topic includes select novel research contributions on fouling in membrane filtration processes. The topic was extended to various membrane processes employed for the treatment of different feeds (seawater, wastewater, freshwater, industrial wastewater, brine, produced water, process stream in food, and biorefineries, etc.). A collection of four articles on fouling in membrane filtration systems was presented, including two original research papers, one review, and one perspective.

Over the past few decades, most research on membrane fouling mainly explores the study of fouling in water treatment processes for seawater desalination and water reuse (Jiang et al., 2017; Meng et al., 2017). In seawater reverse osmosis (SWRO) processes, fouling has been considered a key challenge in desalination plants, contributing significantly to the cost of water produced by increasing the 1) pressure necessary to drive the processes, 2) chemical cleaning, and 3) the membrane replacement frequency (She et al., 2016; Fortunato et al., 2020) Gonzales-Gil et al. performed a clinical membrane autopsy from a lead module of a full-scale SWRO desalination plant. Several analytical techniques were employed to allow a detailed characterization of the fouling. The 
results indicated the accumulation of iron, biofouling, and organic carbon on the membrane surface. The authors attributed the fouling propensity to the inadequate pretreatment operation in the plants. Furthermore, the article addressed the need for reporting the results from membrane autopsy to allow the comparison between different studies and reports. Indeed, despite the importance of the topic, previous research in membrane fouling in desalination processes is often fragmented and contradictory, where the absence of a clear fouling characterization protocol might lead to misinterpretation and bias diagnosis. There is a need to develop a solid fouling autopsy protocol for membrane modules from full-scale plants, encouraging the creation of a database that could be used as guidance on fouling diagnosis and control.

In membrane bioreactor processes for wastewater treatment, the fouling has been mainly associated with its negative effect on the membrane performance, where the development of biofilm on the membrane surface leads to an increase in transmembrane pressure and energy consumption over time (Meng et al., 2017). Sawaya et al. highlighted the positive effect of biofouling on the permeate quality in anaerobic membrane bioreactors. As reported in their perspective article, the formation of biofilm on the membrane surface was found to improve the removal of emerging contaminants as organic micropollutants (OMP). In particular, hydrophobic OMPs showed a higher affinity with the specific biofouling components as extracellular polymeric substances. To this extent, the authors highlighted the necessity to develop fouling mitigation strategies that enable the formation of biofilm while reducing the fouling rate. Indeed, in membrane bioreactors, the additional filtration layer provided by the formation of fouling layer on the membrane surface improves the permeate quality, allowing the enhanced removal of emerging organic contaminants, therefore reducing the environmental impact related to the discharge into the environment.

Research on membrane fouling on other processes and applications outside water treatment has gained increasing attention. The research carried out by Birrenbach et al. focused on the performances of ultrafiltration ceramic membrane for the recovery and purification of protein aggregates. The membrane performance was affected by the interaction between the cell lysate and ovalbumin aggregates. The resistance-in-series model suggested the occurrence of the

\section{REFERENCES}

Ang, W. L., Nordin, D., Mohammad, A. W., Benamor, A., and Hilal, N. (2017). Effect of Membrane Performance Including Fouling on Cost Optimization in Brackish Water Desalination Process. Chem. Eng. Res. Des. 117, 401-413. doi:10.1016/j.cherd.2016.10.041

Charcosset, C. (2006). Membrane Processes in Biotechnology: An Overview. Biotechnol. Adv. 24, 482-492. doi:10.1016/j.biotechadv.2006.03.002

Fortunato, L., Alshahri, A. H., Farinha, A. S. F., Zakzouk, I., Jeong, S., and Leiknes, T. (2020). Fouling Investigation of a Full-Scale Seawater Reverse Osmosis Desalination (SWRO) Plant on the Red Sea: Membrane Autopsy and intermediate pore-blocking fouling mechanism. The filtration performance was strongly affected by the ovalbumin concentration, where a 10 -fold increase in concentration led to an $85 \%$ flux decline. The work provides a better understanding of the impact of fouling during the filtration and separation of protein aggregates.

The increasing use of membrane technology in algal processes has brought to light the importance of understanding the fouling occurring in algal separation processes. Novoa et al. provided a state-of-the-art literature review on fouling influencing factors and mechanisms in membrane-based algal technologies. The algal cells are the main contributors to membrane fouling, although being responsible for the reversible fouling, while the algal organic matter is reported to be responsible for irreversible fouling. The authors highlight that despite recent advances in the field, fouling is the main operation challenge in membrane-based algal processes, presenting major knowledge gaps and therefore requiring further research. Moreover, the research in this area is critical in considering the need to recover the algal biomass deposited on the membrane surface for the further valorization of algal valuable byproducts. Indeed, in many separation processes membrane fouling should not be seen only as a challenge but as a potential resource stream (Zhang et al., 2010).

This Research Topic collection advances understanding of the critical role of fouling in several separation and purification processes. The research gaps identified in this Research Topic highlight challenges and research opportunities in chemical and environmental engineering processes.

\section{AUTHOR CONTRIBUTIONS}

LF drafted the first version of this editorial. All authors contributed, revised, and approved the final version.

\section{ACKNOWLEDGMENTS}

We thank the authors of the papers included in this Research Topic for their valuable contributions and the reviewers for their rigorous comments. We also thank the editorial board of Separation Processes.

Pretreatment Efficiency. Desalination 496, 114536. doi:10.1016/ j.desal.2020.114536

Fortunato, L., Lamprea, A. F., and Leiknes, T. (2020). Evaluation of Membrane Fouling Mitigation Strategies in an Algal Membrane Photobioreactor (AMPBR) Treating Secondary Wastewater Effluent, 708. Science of The Total Environment, 134548. doi:10.1016/J.SCITOTENV.2019.134548

Jiang, S., Li, Y., and Ladewig, B. P. (2017). A Review of Reverse Osmosis Membrane Fouling and Control Strategies. Sci. Total Environ. 595, 567-583. doi:10.1016/ j.scitotenv.2017.03.235

Meng, F., Zhang, S., Oh, Y., Zhou, Z., Shin, H.-S., and Chae, S.-R. (2017). Fouling in Membrane Bioreactors: An Updated Review. Water Res. 114, 151-180. doi:10.1016/j.watres.2017.02.006 
Mohammad, A. W., Ng, C. Y., Lim, Y. P., and Ng, G. H. (2012). Ultrafiltration in Food Processing Industry: Review on Application, Membrane Fouling, and Fouling Control. Food Bioproc. Technol 5, 1143-1156. doi:10.1007/s11947-0120806-9

Scarascia, G., Fortunato, L., Myshkevych, Y., Cheng, H., Leiknes, T., and Hong, P.Y. (2021). UV and Bacteriophages as a Chemical-free Approach for Cleaning Membranes from Anaerobic Bioreactors. Proc. Natl. Acad. Sci. USA 118, e2016529118. doi:10.1073/PNAS.2016529118

She, Q., Wang, R., Fane, A. G., and Tang, C. Y. (2016). Membrane Fouling in Osmotically Driven Membrane Processes: A Review. J. Membr. Sci. 499, 201-233. doi:10.1016/j.memsci.2015.10.040

Takht Ravanchi, M., Kaghazchi, T., and Kargari, A. (2009). Application of Membrane Separation Processes in Petrochemical Industry: a Review. Desalination 235, 199-244. doi:10.1016/ j.desal.2007.10.042

Vu, M. T., Nguyen, L. N., Hasan Johir, M. A., Zhang, X., Nghiem, L. D., and Elimelech, M. (2021). Biogas Sparging to Control Fouling and Enhance Resource Recovery from Anaerobically Digested Sludge Centrate by Forward Osmosis. J. Membr. Sci. 625, 119176. doi:10.1016/ j.memsci.2021.119176
Zhang, X., Hu, Q., Sommerfeld, M., Puruhito, E., and Chen, Y. (2010). Harvesting Algal Biomass for Biofuels Using Ultrafiltration Membranes. Bioresour. Tech. 101, 5297-5304. doi:10.1016/j.biortech.2010.02.007

Conflict of Interest: The authors declare that the research was conducted in the absence of any commercial or financial relationships that could be construed as a potential conflict of interest.

Publisher's Note: All claims expressed in this article are solely those of the authors and do not necessarily represent those of their affiliated organizations, or those of the publisher, the editors and the reviewers. Any product that may be evaluated in this article, or claim that may be made by its manufacturer, is not guaranteed or endorsed by the publisher.

Copyright (c) 2021 Fortunato, Lipnizki and Dumée. This is an open-access article distributed under the terms of the Creative Commons Attribution License (CC BY). The use, distribution or reproduction in other forums is permitted, provided the original author(s) and the copyright owner(s) are credited and that the original publication in this journal is cited, in accordance with accepted academic practice. No use, distribution or reproduction is permitted which does not comply with these terms. 